\title{
The Efficacy, Safety, and Side Effects of Intrapericardial Triamcinolone Treatment in Children with Post-surgical Pericardial Effusion: A Case Series
}

\author{
Manon H. van der Werff ${ }^{1}$ (I) - Hetty J. van der Kamp ${ }^{2}$. Johannes M. P. J. Breur ${ }^{1}$
}

Received: 20 April 2021 / Accepted: 4 August 2021 / Published online: 17 August 2021

(c) The Author(s) 2021

\begin{abstract}
Intrapericardial triamcinolone can be used to treat chronic pericardial effusion (PE) in adults; however, pediatric data are lacking. In this case series we aim to evaluate the efficacy, safety, and side effects of intrapericardial triamcinolone in children with PE. The incidence and treatment of post-surgical PE from 2009 to 2019 were determined using the institutional surgical database and electronic patient records. Furthermore, a retrospective analysis of efficacy, safety, and side effects of intrapericardial triamcinolone treatment for chronic post-surgical PE was performed. The incidence of postoperative PE requiring treatment was highest after atrial septal defect (ASD) closure when compared to other types of cardiac surgery $(9.7 \%$ vs $4.3 \%)$. Intrapericardial treatment with triamcinolone resolved pericardial effusion in 3 out of 4 patients. All patients developed significant systemic side effects. Surgical ASD closure is associated with an increased risk of development of $\mathrm{PE}$ requiring treatment. Intrapericardial triamcinolone is an effective treatment for chronic postoperative PE in children, but is always associated with significant systemic side effects. Close monitoring and treatment of adrenal insufficiency are mandatory in these cases.
\end{abstract}

Keywords Pericardial effusion · Intrapericardial $\cdot$ Triamcinolone $\cdot$ Adrenal insufficiency

\section{Introduction}

The reported prevalence of postoperative pericardial effusion (PE) ranges between 1 and 53\% [1-8] in children and adults. PE is often responsive to anti-inflammatory therapy, but in a minority of the cases PE becomes chronic. Possible treatment options for chronic PE are pericardiocentesis, creation of a surgical pericardial window, and intrapericardial triamcinolone. Intrapericardial triamcinolone has been associated with dramatic symptomatic improvement in adults

Manon H. van der Werff, Hetty J. van der Kamp, and Johannes M.P.J. Breur take responsibility for all aspects of the reliability and freedom from bias of thedata presented and their discussed interpretation.

Manon H. van der Werff

m.h.vanderwerff@students.uu.nl

1 Department of Pediatric Cardiology, University Medical Center, PO Box 85090, 3508 AB Utrecht, The Netherlands

2 Department of Pediatric Endocrinology, University Medical Center, PO Box 85090, 3508 AB Utrecht, The Netherlands
[9]. There are no recommendations on intrapericardial triamcinolone treatment of PE in children. It is only known that corticosteroid use should be restricted because of the side effects [10]. The aim of this study was to establish the incidence of $\mathrm{PE}$ requiring treatment after pediatric cardiac surgery and to evaluate the efficacy, safety, and side effects of intrapericardial triamcinolone treatment in chronic postoperative pediatric PE.

\section{Methods}

\section{Study Population}

The institutional surgical database was used to identify all pediatric patients who received cardiac surgery for congenital heart disease (CHD) in 2019 and all surgical atrial septal defect (ASD) closures from 2009 to 2019. Electronic patient records and echo database were checked for postoperative occurrence and treatment of PE. PE treatment was initiated when echocardiography showed hemodynamically significant PE with or without clinical signs of cardiac tamponade. 
Furthermore all patients receiving intrapericardial triamcinolone treatment between 2014 and July 2020 were identified using the hospital database. Medical records, echocardiography reports, laboratory markers, medication, and operation reports from before and after the treatment with triamcinolone were reviewed.

\section{Intervention}

Intrapericardial triamcinolone was administered to patients with postoperative chronic ( $>3$ months) and/or recurrent $\mathrm{PE}$, despite other treatments. Installation of triamcinolone (300 mg/m² - according to Maisch et al. [9]) was performed using a pigtail drain after pericardiocentesis. After $24 \mathrm{~h}$ the remaining pericardial fluid was aspirated and the drain was removed.

\section{Outcome}

The outcome measures were efficacy of PE treatment, the presence of side effects, and the adrenal function. The efficacy of triamcinolone was measured by the persistence or disappearance of PE on echocardiograms performed after treatment. The presence of side effects was extracted from the medical records. The adrenal function was determined by low-dose (1mcg) ACTH-tests.

\section{Results}

All patients who developed significant post-surgical PE were primarily treated with prednisone. In the CHD group (ASD surgery excluded) $4.3 \%$ (7/164) required PE treatment versus 9.7\% (28/289) in the ASD group. Prednisone treatment alone was effective in all patients in the CHD group (7/7) and in
$82 \%$ (23/28) of the ASD group. Recovery occurred after a mean of 8 days (range 4-16) in the CHD group and after 7 days (range 4-27) in the ASD group. Pericardiocentesis was performed in $1.7 \%$ (5/289 patients) of the ASD group.

Four patients were treated with intrapericardial triamcinolone treatment. Patient characteristics and outcome are summarized in Table 1. Three of these patients underwent surgical ASD closure and one patient underwent epicardial pacemaker implantation. The time between onset of PE and triamcinolone administration varied between 1.5 and 9 months. All patients were treated with prednisone and pericardiocentesis (1-4 times) before triamcinolone administration. One patient was treated with intravenous immunoglobulins (IVIG) [11]. In three out of four patients PE did not reoccur after triamcinolone administration. In one patient PE reoccurred and a surgical pericardial window was created.

The course of the side effects of triamcinolone treatment is summarized in Table 2. All patients developed symptoms within 3 weeks lasting up to several years.

\section{Case Reports}

\section{Patient 1}

A 10-year-old girl with multiple congenital dysmorphisms and a spontaneously closed ventricular septal defect underwent surgical ASD closure. PE developed 1 month later and prednisone was started. In a period of 9 months prednisone was unsuccessfully tapered 4 times. Two months after prednisone initiation a Cushingoid face developed and after 5 months she developed fatigue (low energy levels, early bedtimes, and missing school). Additional treatment consisted of pericardiocentesis IVIG (twice) and colchicine [10], all without success. After 9 months of persisting

Table 1 Patient characteristics and the efficacy of triamcinolone

\begin{tabular}{|c|c|c|c|c|c|c|c|}
\hline No & Age (years) / sex & Operation & $\begin{array}{l}\text { Time between } \\
\text { onset PE and } \\
\text { triamcinolone } \\
\text { administration }\end{array}$ & $\begin{array}{l}\text { Number of times } \\
\text { pericardiocentesis } \\
\text { before triamci- } \\
\text { nolone administra- } \\
\text { tion }\end{array}$ & $\begin{array}{l}\text { Number of times } \\
\text { prednisone was } \\
\text { started or dose } \\
\text { was increased } \\
\text { before triamci- } \\
\text { nolone administra- } \\
\text { tion }\end{array}$ & $\begin{array}{l}\text { Number of times } \\
\text { treated with IVIG } \\
\text { before triamci- } \\
\text { nolone adminis- } \\
\text { tration }\end{array}$ & $\begin{array}{l}\text { Developed reoc- } \\
\text { currence } \\
\text { PE after triamci- } \\
\text { nolone adminis- } \\
\text { tration }\end{array}$ \\
\hline 1 & $11 / \mathrm{F}$ & $\begin{array}{l}\text { ASD surgical } \\
\text { closure }\end{array}$ & 9 months & 1 & 4 & 2 & No \\
\hline 2 & $11 / \mathrm{M}$ & $\begin{array}{l}\text { Pacemaker } \\
\text { implantation }\end{array}$ & 2.5 months & 1 & 2 & 0 & No \\
\hline 3 & $1 / \mathrm{F}$ & $\begin{array}{l}\text { ASD surgical } \\
\text { closure }\end{array}$ & 7 months & 4 & 2 & 0 & No \\
\hline 4 & $14 / \mathrm{M}$ & $\begin{array}{l}\text { ASD surgical } \\
\text { closure }\end{array}$ & 1.5 months & 3 & 2 & 0 & Yes \\
\hline
\end{tabular}

$P E$ pericardial effusion, $I V I G$ intravenous immunoglobulin, $A S D$ closure atrial septal defect closure 
Table 2 Specifics of the symptoms after triamcinolone administration

\begin{tabular}{|c|c|c|c|c|}
\hline No & $\begin{array}{l}\text { Time between triamcinolone } \\
\text { administration and start symp- } \\
\text { toms }\end{array}$ & Type of symptoms & Duration of symptoms & $\begin{array}{l}\text { Time between triamcinolone } \\
\text { administration and adequate } \\
\text { ACTH-test }\end{array}$ \\
\hline 1 & 1 week & Fatigue, low energy levels & Not clear & 1 year and 9 months \\
\hline 2 & 1 week & $\begin{array}{l}\text { Fatigue, easily tired, irritable, quickly bad- } \\
\text { tempered }\end{array}$ & 3 years and 5 months ${ }^{\mathrm{a}}$ & Not adequate yet \\
\hline 3 & 1 day & $\begin{array}{l}\text { Fatigue, low energy levels, whiny, bad-tem- } \\
\text { pered, mood swings, restless }\end{array}$ & 4 months $^{\mathrm{a}}$ & Not performed yet \\
\hline 4 & 3 weeks & $\begin{array}{l}\text { Fatigue, low energy levels, decreased fitness, } \\
\text { difficulty falling asleep }\end{array}$ & 3 years and 7 months & 3 years and 7 months \\
\hline
\end{tabular}

${ }^{\text {a }}$ Still ongoing

ACTH-test adrenocorticotropic hormone test

PE pericardiocentesis was performed with administration of $420 \mathrm{mg}$ triamcinolone and $80 \mathrm{mg}$ gentamycin (sclerotherapy). Three days after triamcinolone administration, the morning cortisol concentration was $<0.02 \mu \mathrm{mol} / \mathrm{L}$. Thereafter PE did not reoccur. However she developed extreme fatigue. Hydrocortisone supplementation (12 mg/m2) was added for 8 months because of those signs and symptoms. Five months after hydrocortisone initiation a small improvement in fitness was seen, but it took one year and 9 months (after triamcinolone administration) until the ACTH-test normalized.

\section{Patient 2}

An 11-year-old boy underwent epicardial pacemaker implantation for paroxysmal atrioventricular block. PE occurred 1 week later and prednisone was started. Because of progressive $\mathrm{PE}$ and echocardiographic signs of tamponade pericardiocentesis was performed. Two attempts were made to taper prednisone without success. Two months after the start of prednisone a Cushingoid face developed. After 2.5 months a second pericardiocentesis was performed with administration of $420 \mathrm{mg}$ triamcinolone. On the same day colchicine was started and prednisone was continued. There has been no recurrence of $\mathrm{PE}$ after the triamcinolone administration. One week after triamcinolone administration he developed symptoms of fatigue, expressed by being easily tired, irritable, and bad-tempered. Prednisone and colchicine were tapered within 2 and 3.5 months, respectively. Because of fatigue symptoms, expressed by low energy levels, missing school, and not having fun, prednisone was restarted 9 months later and the dose increased considerably in the following months. His listless feeling and increased need of sleep persisted despite a "physiologic" morning dose of prednisone. No other explanation for the fatigue could be established. Symptoms persist to date and ACTH-tests remain inadequate.

\section{Patient 3}

A 5-month-old girl underwent surgical ASD closure. PE with tamponade occurred one month later for which immediate pericardiocentesis was performed and prednisone was started. In a period of 7 months two attempts to taper prednisone were unsuccessful despite the addition of colchicine in the 6th month. Furthermore pericardiocentesis had to be performed twice. In the 6th month fatigue symptoms started, expressed by being easily tired, bad-tempered, and whiny. After the 7th month $140 \mathrm{mg}$ triamcinolone was administered intrapericardially without recurrence of PE thereafter. One day after triamcinolone treatment fatigue symptoms started, expressed by being bad-tempered, listless, whiny, and having low energy levels. Three days after triamcinolone administration, the morning cortisol concentration was $<0.02 \mu \mathrm{mol} / \mathrm{L}$. Because of these symptoms hydrocortisone $\left(12 \mathrm{mg} / \mathrm{m}^{2}\right)$ was started. Symptoms like being restless, mood swings, being bad-tempered, and sleeping badly continued for 2 months. Because of the suspicion of adrenal insufficiency, hydrocortisone was tapered. Up till now, the symptoms persist and hydrocortisone therapy is still necessary.

\section{Patient 4}

A 14-year-old boy with a history of surgically corrected esophageal atresia underwent surgical ASD closure. Two days later cardiac tamponade developed and acute pericardiocentesis was performed. After 1 week a second cardiac tamponade developed and another pericardial drainage was performed. Prednisone, NSAID, and colchicine were started. Three weeks after initiation of prednisone, a Cushingoid face was developed. One attempt was made to taper prednisone, which resulted in a relapse of $\mathrm{PE}$ and another pericardiocentesis. One and a half month after the onset of $\mathrm{PE}$, pericardiocentesis was performed and $320 \mathrm{mg}$ triamcinolone was administered intrapericardially. Nevertheless PE reoccurred and 1 week later a 
surgical pericardial window was created with continuation of prednisone treatment without reoccurrence of PE. One week later fatigue symptoms started, expressed by low energy levels, decreased fitness, and difficulty falling asleep causing tiredness during the day. As a result this patient was only able to attend half days at school. Melatonin and rehabilitation were initiated to improve sleep and physical fitness. Three months after creation of the pericardial window, prednisone was completely tapered. However it took 3 years and 4 months to obtain a normal ACTH-test. During this period the fatigue symptoms were varyingly present, only improving at the time of the adequate ACTH-test.

\section{Discussion}

The incidence of pericardial effusion requiring medical treatment is high after surgical ASD closure (9.7\%). In the vast majority of cases oral anti-inflammatory therapy led to complete resolution of PE. Chronic PE developed in 10\% of patients after surgical ASD closure. The intrapericardial administration of triamcinolone resolved chronic PE in 3 out of 4 patients. However all patients had long lasting serious side effects.

The incidence of PE (requiring at least prednisone) after ASD closure was more than twice as high as the incidence after all cardiac surgeries (9.7\% versus $4.3 \%$ ). These findings are in line with other reports identifying ASD closure as an independent risk factor for readmission with PE and intervention [12]. It is assumed that chronic volume overload of the right atrium may support altered mechanics of PE production, combined with the inflammatory reaction secondary to the pericardiotomy and right atriotomy.

To the best of our knowledge, this is the first study evaluating the efficacy of intrapericardial triamcinolone in children. Maisch et al. [9] treated 84 adult patients with intrapericardial triamcinolone- 54 patients with $600 \mathrm{mg} / \mathrm{m}^{2}$ and 30 patients with $300 \mathrm{mg} / \mathrm{m}^{2}$ - preventing PE recurrence in $92.6 \%$ vs. $86.7 \%$ of patients after 3 months and in $86.0 \%$ vs $82.1 \%$ after 1 year. In this study intrapericardial triamcinolone $\left(300 \mathrm{mg} / \mathrm{m}^{2}\right)$ was immediately effective in three of four patients with chronic postoperative and/or recurrent PE. It is debatable whether or not a higher triamcinolone dose could have changed the course of the unresponsive patient. A lower dose than $300 \mathrm{mg} / \mathrm{m}^{2}$ was never considered, as those patients did not respond to already high doses of prednisone. However, the results suggest that a lower initial dose may be considered in a dose-response study.

All patients treated with intrapericardial triamcinolone developed side effects shortly after administration including fatigue, low energy levels, being easily tired, and bad-tempered. Patient 2 and 4 newly developed these symptoms after the administration and patient 1 and 3 had worsening of these symptoms not otherwise explained. All patients had good systolic and diastolic function, therefore a cardiac cause of the side effects is unlikely. The side effects lasted at least 2 years (excluding patient 3 ), much longer than the known duration of side effects for oral corticosteroids [12].

Although it may be assumed that intrapericardial administration of corticosteroids avoids major side effects as seen in systemic treatment, iatrogenic Cushing's syndrome was described earlier by Grubb et al. [13]. It may be recommended to monitor the morning plasma cortisol shortly after treatment to confirm adrenal suppression. However, this is only a warning sign, as it takes 14-21 days to develop adrenal insufficiency. A concentration $>0.5 \mu \mathrm{mol} / \mathrm{L}$ (depending on the assay used) excludes triamcinolone absorption and systemic side effects.

Maisch et al. [9] report that iatrogenic Cushing syndrome developed in $13.3 \%$ of adult patients receiving $300 \mathrm{mg} / \mathrm{m}^{2}$ intrapericardial triamcinolone, without specifying their symptoms. Known symptoms of Cushing syndrome in children are growth retardation, delayed puberty, obesity, hypertension, severe fatigue, mood swings, anxiety, irritability, and loss of emotional control [14]. The patients in our case study had all those systemic side effects.

Although triamcinolone has a 1.25 stronger anti-inflammatory effect than prednisone and a longer biologic half-life, there must be another explanation for the prolonged duration of adrenal insufficiency and the extreme side effects despite supplementation of a maintenance dose of hydrocortisone [15].

Intrapericardial treatment with agents like steroids, gentamycin or chemotherapy may be associated with the development constrictive pericarditis due to sclerosing properties of the medication [10]. However this complication has not been described for triamcinolone to date. Diastolic function was closely monitored and remained normal in all patients.

\section{Recommendation}

Intrapericardial triamcinolone is of additional value in the treatment of chronic pediatric postoperative pericardial effusion. However adrenal insufficiency is likely to develop. Therefore treatment should always be performed in close collaboration with a pediatric endocrinologist.

\section{Limitations}

The number of patients treated with intrapericardial triamcinolone administration is low. It is hard to draw definite conclusions on treatment efficacy with these low numbers. An international registration could help to develop optimal treatment for chronic postoperative PE. 


\section{Conclusion}

PE is more common after pediatric surgical ASD closure compared to other congenital heart surgeries. The majority of cases can be managed by anti-inflammatory treatment, such as prednisone. Chronic and/or recurrent post-surgical PE can successfully be treated with intrapericardial triamcinolone administration in the majority of cases, but is always associated with serious systemic side effects. Therefore, patients receiving intrapericardial triamcinolone therapy should be closely monitored for development and treatment of adrenal insufficiency.

Supplementary Information The online version contains supplementary material available at https://doi.org/10.1007/s00246-021-02704-z

\section{Acknowledgements None.}

Supporting Information Supplementary Table S1-Data Table 1.

Author Contribution MVDW performed Conceptualization, Validation, Investigation, Writing-Original draft, and Visualization. HVDK performed Conceptualization, Validation, Resources, Writing-Review $\&$ Editing, Visualization, and Supervision. HB performed Conceptualization, Validation, Resources, Writing-Review \& Editing, Visualization, and Supervision.

Funding This research did not receive any specific grant from funding agencies in the public, commercial, or not-for-profit sectors.

Data Availability Data from Table S1 is available.

Code Availability Not applicable.

\section{Declarations}

Conflicts of interest The authors have no conflicts of interest to declare.

Ethical Approval For this type of study, formal consent is not required.

Informed Consent Informed consent was obtained from all individual participants and/or legal guardians included in the study.

Open Access This article is licensed under a Creative Commons Attribution 4.0 International License, which permits use, sharing, adaptation, distribution and reproduction in any medium or format, as long as you give appropriate credit to the original author(s) and the source, provide a link to the Creative Commons licence, and indicate if changes were made. The images or other third party material in this article are included in the article's Creative Commons licence, unless indicated otherwise in a credit line to the material. If material is not included in the article's Creative Commons licence and your intended use is not permitted by statutory regulation or exceeds the permitted use, you will need to obtain permission directly from the copyright holder. To view a copy of this licence, visit http://creativecommons.org/licenses/by/4.0/.

\section{References}

1. Elias MD, Glatz AC, O'Connor MJ, Schachtner S, Ravishankar C, Mascio CE et al (2017) Prevalence and risk factors for pericardial effusions requiring readmission after pediatric cardiac surgery. Pediatr Cardiol 38(3):484-494. https://doi.org/10.1007/ s00246-016-1540-2

2. Imazio M, Brucato A, Rovere ME, Gandino A, Cemin R, Ferrua $S$ et al (2011) Colchicine prevents early postoperative pericardial and pleural effusions. Am Heart J 162(3):527-32.e1. https://doi. org/10.1016/j.ahj.2011.05.017

3. Cheung EWY, Ho SA, Tang KKY, Chau AKT, Chiu CSW, Cheung YF (2003) Pericardial effusion after open heart surgery for congenital heart disease. Heart 89(7):780-783. https://doi.org/ 10.1136/heart.89.7.780

4. Yip AS, Chau EM, Chow WH, Kwok OH, Cheung KL (1997) Pericardial effusion in adults undergoing surgical repair of atrial septal defect. Am J Cardiol 79(12):1706-1708. https://doi.org/10. 1016/s0002-9149(97)00231-2

5. Prabhu AS, Ross RD, Heinert MR, Walters HL 3rd, Hakimi M (1996) Decreased incidence of postoperative pericardial effusions after cardiac surgery for congenital heart disease. Am J Cardiol 77(9):774-776. https://doi.org/10.1016/s0002-9149(97)89218-1

6. Dalili M, Zamani H, Aarabi-Moghaddam M (2012) Pericardial effusion after pediatric cardiac surgeries: a single center observation. Res Cardiovasc Med 1(1):28-32. https://doi.org/10.5812/ cardiovascmed.4601

7. Kuvin JT, Harati NA, Pandian NG, Bojar RM, Khabbaz KR (2002) Postoperative cardiac tamponade in the modern surgical era. Ann Thorac Surg 74(4):1148-1153. https://doi.org/10.1016/ s0003-4975(02)03837-7

8. Clapp SK, Garson A Jr, Gutgesell HP, Cooley DA, McNamara DG (1980) Postoperative pericardial effusion and its relation to postpericardiotomy syndrome. Pediatrics 66(4):585-588

9. Maisch B, Ristić AD, Pankuweit S (2002) Intrapericardial treatment of autoreactive pericardial effusion with triamcinolone; the way to avoid side effects of systemic corticosteroid therapy. Eur Heart J 23(19):1503-1508. https://doi.org/10.1053/euhj.2002. 3152

10. Adler Y, Charron P (2015) The 2015 ESC Guidelines on the diagnosis and management of pericardial diseases. Eur Heart $\mathrm{J}$ 36(42):2873-2874. https://doi.org/10.1093/eurheartj/ehv479

11. Wendelin G, Fandl A, Beitzke A (2008) High-dose intravenous immunoglobulin in recurrent postpericardiotomy syndrome. Pediatr Cardiol 29(2):463-464. https://doi.org/10.1007/ s00246-007-9025-y

12. Brown ES, Chandler PA (2001) Mood and cognitive changes during systemic corticosteroid therapy. Prim Care Companion J Clin Psychiatry 3(1):17-21. https://doi.org/10.4088/pcc.v03n0104

13. Paragliola RM, Papi G, Pontecorvi A, Corsello SM (2017) Treatment with synthetic glucocorticoids and the hypothalamus-pituitary-adrenal axis. Int J Mol Sci 18(10):2201. https://doi.org/10. 3390/ijms 18102201

14. Jameson JL et al (eds) (2016) Cushing's syndrome. In: Endocrinology: Adult and Pediatric, 7th edn. Saunders Elsevier, Philadelphia, PA

15. Paragliola RM, Papi G, Pontecorvi A, Corsello SM (2017) Treatment with synthetic glucocorticoids and the Hypothalamus-Pituitary-Adrenal Axis. Int J Mol Sci 18(10):2201. https://doi.org/10. 3390/ijms 18102201

Publisher's Note Springer Nature remains neutral with regard to jurisdictional claims in published maps and institutional affiliations. 